\title{
Durability of glass-fiber-reinforced polymer composites in an alkaline environment
}

Joshua L. Mounts

West Virginia University

Follow this and additional works at: https://researchrepository.wvu.edu/etd

\section{Recommended Citation}

Mounts, Joshua L., "Durability of glass-fiber-reinforced polymer composites in an alkaline environment" (2007). Graduate Theses, Dissertations, and Problem Reports. 1804.

https://researchrepository.wvu.edu/etd/1804

This Thesis is protected by copyright and/or related rights. It has been brought to you by the The Research Repository @ WVU with permission from the rights-holder(s). You are free to use this Thesis in any way that is permitted by the copyright and related rights legislation that applies to your use. For other uses you must obtain permission from the rights-holder(s) directly, unless additional rights are indicated by a Creative Commons license in the record and/ or on the work itself. This Thesis has been accepted for inclusion in WVU Graduate Theses, Dissertations, and Problem Reports collection by an authorized administrator of The Research Repository @ WVU. For more information, please contact researchrepository@mail.wvu.edu. 


\title{
Durability of Glass-Fiber-Reinforced Polymer Composites in an Alkaline Environment
}

\author{
Joshua L. Mounts
}

\author{
Thesis submitted to the \\ College of Engineering and Mineral Resources \\ at West Virginia University \\ in partial fulfillment of the requirements for the degree of
Master of Science In

\section{Chemical Engineering} \\ Department of Chemical Engineering
}

\author{
Eung H. Cho, Ph.D., Chair \\ Rakesh K. Gupta, Ph.D. \\ Department of Chemical Engineering \\ Dr. Hota V. Gangarao, Ph.D. \\ Department of Civil Engineering
}

Morgantown, West Virginia

2007

Keywords: Vinyl Ester, Urethane, Urethane modified, glass fiber, reinforced polymer, GFRP, Alkaline aging, sustained load, diffusion studies

Copyright 2007 Joshua L. Mounts 


\section{ABSTRACT \\ Durability of Glass-Fiber-Reinforced Polymer Composites in an Alkaline Environment}

Joshua L. Mounts

This study investigated the aging of urethane modified vinyl ester (UMVE) and urethane GFRP (glass fiber reinforced polymer) when exposed to alkaline solution. Samples from both composites were exposed to alkaline solution with sustained load for six months. The sustained load on each sample was approximately $34.5 \mathrm{MPa}$ or $16-20$ percent of their tensile strength. The second experiment exposed both types of GFRP to alkaline solution without load for six months. The final experiment determined the alkaline solution diffusion coefficients through each GFRP polymer by measuring the change in mass of each sample as a function of time.

After the GFRP samples were aged for six months, their tensile strengths were measured and compared with the tensile strength of non-aged samples to measure the aging effect. It was found that alkaline solution alone (without sustained load) did not significantly reduce or change the tensile strength of any of the samples. However, the presence of sustained load greatly increased the aging effect. UMVE GFRP experienced a tensile strength reduction of 27.3 percent while urethane GFRP lost 57.5 percent of its original tensile strength. In all cases, the maximum alkaline solution uptake for urethane GFRP samples was more than double the uptake of UMVE GFRP samples. The more severe aging effect seen in urethane GFRP samples may be directly related to the increased alkaline solution uptake observed for the urethane based samples. 


\section{ACKNOWLEDGEMENTS}

I would like to express my gratitude and appreciation to the Department of Chemical Engineering and its chairperson, Dr. Dady Dadyburjor, for allowing me this fantastic opportunity to pursue an M.S. degree in the department. Also, I must thank Mr. Nelson Douglas from Reichhold who most graciously provided our lab with more than enough urethane and urethane modified vinyl ester resins.

The work would be impossible without the always involved Dr. Eung Cho. His unrelenting pursuit to see the work through and guide all of his students beyond graduation is very evident and much appreciated. I would also like to acknowledge Dr. Rakesh Gupta for his willingness to serve as a member of my examining committee and his willingness to accept my application as an M.S. candidate. I must also thank Dr. Hota GangaRao for his always open door and willingness to provide direction when data did not make sense.

I would also like to thank Mrs. Linda Rogers for her willingness to help with the non-research related problems that arose and Dr. John Zondlo for always making his class interesting.

Beyond the educational and technical guidance, my deepest thanks must go to my mother and father who made my undergraduate and graduate education possible. Their love, phone calls, visits, and money will never go unappreciated. I must also express my thanks and love to my brother, Jordan, for his weekly phone calls and updates on Mountaineer sports.

My deepest love, appreciation, and thanks to my wife, Cassie, who endured, along with me, the long nights of homework, studying, and the writing of this thesis. 


\section{TABLE OF CONTENTS}

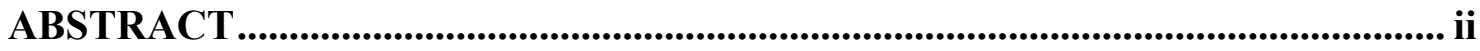

ACKNOWLEDGMENTS ......................................................................................... iii

TABLE OF CONTENTS ..................................................................................... iv

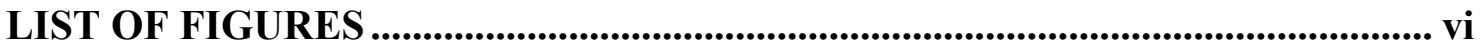

LIST OF TABLES .................................................................................................. vii

CHAPTER 1 INTRODUCTION ............................................................................1

CHAPTER 2 THEORY .............................................................................................................3

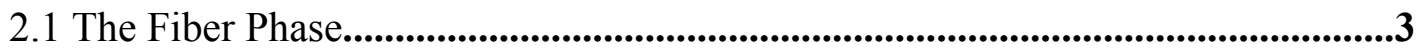

2.2 Stress-Strain Characteristics ...............................................................................4

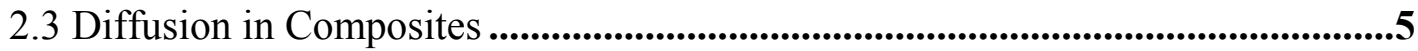

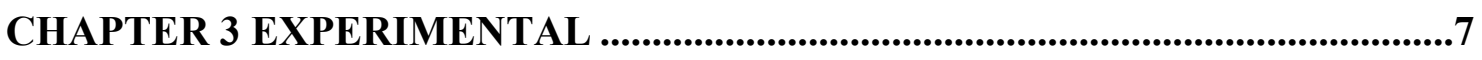

3.1 Materials .............................................................................................................7

3.2 Sample Preparation ..............................................................................................7

3.3 Void Fraction Measurement ...............................................................................................8

3.4 Tensile Strength Measurement .............................................................................9

3.5 Aging Test with Load .............................................................................................10

3.6 Aging Test without Load .................................................................................12

3.7 Absorption Test for UMVE and urethane GFRP.............................................12

3.8 Absorption Test for Neat Resin UMVE and Urethane ......................................13

CHAPTER 4 RESULTS ...................................................................................14

4.1 Tensile Strength and Young Modulus Measurement..............................................14 
4.2 Aging Test with Load ......................................................................................................14

4.3 Aging Test without Load .................................................................................16

4.4 GFRP Absorption Test...................................................................................................17

4.5 Neat Urethane and UMVE Absorption Test.............................................................23

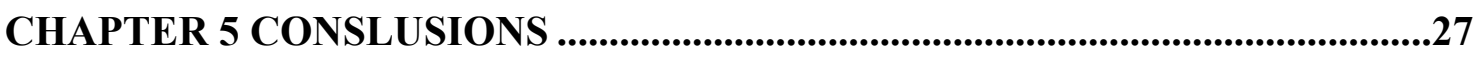

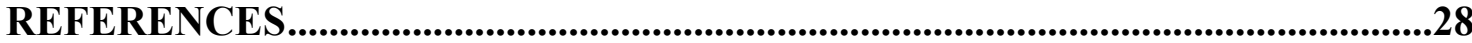




\section{LIST OF FIGURES}

Figure 1. General stress / strain relationship for elastic materials ......................................4

Figure 2. Sustained load test assembly .................................................................................10

Figure 3. Reinforcement tabs after application to sample - side view............................11

Figure 4. Plot according to Fickian model for absorption of alkali into urethane GFRP ....................................................................18

Figure 5. Linear plot for the early stage absorption into urethane GFRP......................19

Figure 6. Plot according to Fickian model for absorption of alkali into UMV E GFRP ................................................................................21

Figure 7. Linear plot for the early stage absorption into UMVE GFRP.........................22

Figure 8. Plot according to Fickian model for absorption of alkali into urethane neat resin...........................................................................24

Figure 9. Plot according to Fickian model for absorption of alkali into UMVE neat resin...........................................................................25 


\section{LIST OF TABLES}

Table 1. Comparison of Non-aged Mechanical Properties between UMVE and Urethane GFRP Samples ............................................................................................14

Table 2. Tensile Strength Results for Aging with Load ....................................................15

Table 3. Tensile Strength Results for Aging without Load ...............................................16

Table 4. Diffusion Coefficients for GFRPs and Neat Resins ..........................................26 


\section{CHAPTER 1}

\section{INTRODUCTION}

Steel reinforcement for concrete has been in use for many years and has been studied extensively. However, steel concrete reinforcement has a high susceptibility to corrosion due to highly alkaline concrete pore solution $(\sim \mathrm{pH} 13.2)$. As a result of this high susceptibility, alternative materials that can replace steel reinforcement are being sought. One such material is glass fiber reinforced polymer (GFRP). Polymers are superior for corrosion resistance when compared to carbon steel, but lack the load bearing ability of steel. However, when combined with E-glass fiber as the composite load bearing component, a polymer matrix with E-glass fiber possesses great potential for replacing steel rebar in concrete. One drawback to GFRP reinforcement is a lack of long-term durability data. ${ }^{(1)}$ GFRP contains a load bearing glass fiber structure bonded with a polymer matrix to maintain the proper stiffness and load distribution within the composite material. Although many types of fiber reinforced polymers (FRPs) exist, GFRP has been in the forefront of investigation due to the relatively low cost when compared with others, such as carbon FRP (i.e. CFRP) or Aramid FRP (i.e. AFRP).

FRPs have been in use for many years in the aerospace, marine, and military fields. ${ }^{(2)}$ However, application in corrosive infrastructure environments, such as Portland cement, requires additional long term aging studies. Many infrastructure applications require a material lifespan of 75 years. Prior studies suggest that upon exposure to alkaline environments, FRPs can

experience tensile strength reductions up to $64 \%$ during the testing period. ${ }^{(3)}$ A large reduction in tensile strength is a very serious problem when using the composite in bridge decking, buildings, and other civil structures. Therefore, more studies should be conducted to better understand the aging of GFRP in concrete environments. 
The polymer matrix serves a key role, to protect the fibers from harsh environments. Most current studies involving GFRP resistance to alkaline attack focus on vinyl ester as the primary polymer of construction ${ }^{(4)}$. However, Vijay and GangaRao observed superior resistance to alkaline attack using GFRPs constructed with E-glass fiber and urethane modified vinyl ester. ${ }^{(3)}$ Their results indicated that urethane modified vinyl ester (UMVE) GFRP resists aging better than isocyanurate vinyl ester GFRP when exposed to alkaline solution with and without load. Based on their results, a study to compare urethane and urethane modified vinyl ester resin would be very appropriate.

The primary objective of this study is to determine the change in tensile strength of two types of GFRP composites upon aging in alkaline solution. GFRP with a urethane matrix and GFRP with a urethane-modified vinyl ester matrix will makeup the two sample types. GFRP aging will be simulated by exposing the samples to alkaline solution for 6 months without stress and with a sustained stress of $34.5 \mathrm{MPa}$. The diffusion coefficient of alkaline solution into the GFRP samples will be determined by measuring their mass as a function of time, and then utilizing a Fickian diffusion model. 


\section{CHAPTER 2}

\section{THEORY}

FRPs (Fiber reinforced polymers) are composed of two primary components or phases. All FRPs contain a load carrying fiber phase with a polymer matrix surrounding the fibers. The polymer phase serves three purposes, to distribute stresses throughout the fiber phase, maintain the orientation of the fibers, and to act as a barrier between the fiber and corrosive environment such as alkaline solution.

\subsection{The Fiber Phase}

FRP fibers are the primary load bearing component. The strength of a particular FRP sample is primarily determined by the mechanical properties of the fiber. In use today are carbon, glass, and aramid fibers. The various fibers can be found in the form of filaments, strands, or rovings. Glass fibers are the most economical fiber for GFRPs because of their availability and low price. Although carbon fibers have a superior stiffness and inertness, the relative cost when compared to glass fibers still dictates the use of glass fibers.

There are several different types of glass fiber, E-, Z-, A-, C-, and S-. The primary difference lies in their specific chemical compositions. E-glass fibers are most commonly used for GFRP applications, due particularly to their excellent tensile strength and electrical insulating properties besides being low cost when compared with other fibers. ${ }^{(4)}$ However, all glass fibers are very susceptible to alkaline environments, more so than carbon or aramid fibers. Their susceptibility is primarily accredited to the presence of silica in the glass fibers. Silica in the fibers reacts with hydroxyl ions in the surrounding alkaline environment based on the following chemical reaction:

$$
\mathrm{SiO}_{2}+4 \mathrm{OH}^{-} \rightarrow \mathrm{SiO}_{4}^{4-}+2 \mathrm{H}_{2} \mathrm{O}
$$


After this initial reaction, the $\mathrm{SiO}_{4}^{4-}$ ions continue to react with metal ions (i.e. $\mathrm{Ca}^{2+}, \mathrm{K}^{+}$, and $\mathrm{Na}^{+}$) in the alkaline solution to produce hydrated silicates (i.e. calcium silicate hydrate) on the surface of the fibers. ${ }^{(5)}$ As the reaction progresses, the glass fibers lose stiffness and tensile strength as the silica is consumed. The resultant effect is an overall loss of composite strength.

\subsection{Stress-Strain Characteristics}

Composite materials generally demonstrate elastic behavior in a stress-strain diagram as shown in Figure 1.

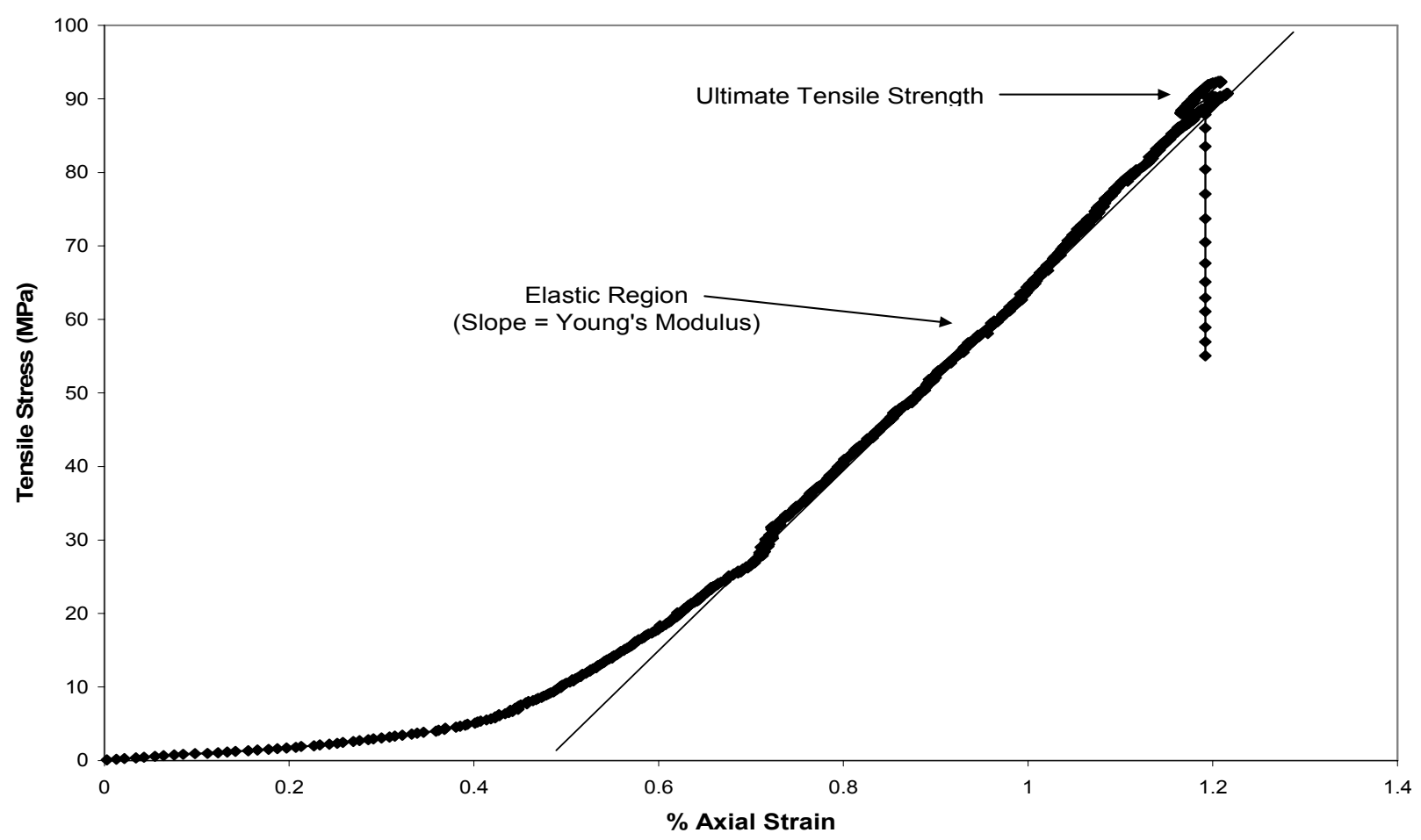

Figure 1. General stress / strain relationship for elastic materials

At the start of the test, very little stress is applied to the GFRP sample yet the sample experiences significant strain. This anomaly is due to micro-stretching within the composite and straightening of the sample as the initial load is applied. Micro-stretching can occur at the polymer / matrix interface, within the polymer matrix, or within the fibers. As load is applied the 
sample finds its strongest configuration by allowing fibers, polymer chains, and cross-linking bonds to rearrange in order to maintain the sample's primary configuration.

Many samples form a gradual bend as the polymer cures before stress / strain testing. This "natural" bend results in sample strain during the beginning of the tensile strength test as the sample is strained into a straight configuration. When the sample reaches a straight position and no longer needs to bend, the composite fibers are stressed as they attempt to maintain their primary and strongest configuration. While the fibers are stressed, the composite experiences elastic deformation. Elastic deformation is characterized by a linear increase of stress vs. strain, indicated in Figure 1. When the composite reaches its maximum tensile stress, the sample quickly fractures and the stress is relieved.

GFRPs do not generally experience plastic deformation. When samples are plastically deformed, their stress-strain relationship appears non-linear. When the stress is removed, the sample does not return to its original configuration unlike elastic deformation.

\subsection{Diffusion in Composites}

Diffusion properties of polymers and GFRPs have been studied in great depth. The Fickian diffusion model has become the most common model for moisture transport through a thin polymer film. ${ }^{(6)}$ Fick's second law is given as:

$$
\frac{\partial c}{\partial t}=D \frac{\partial^{2} c}{\partial x^{2}}
$$

where $\mathrm{c}$ is the concentration of the diffusing species (alkaline solution) at time $\mathrm{t}$ and $D$ is the diffusion coefficient or diffusivity.

The solution of Equation 2 is given by Equation 3 in terms of mass uptake: ${ }^{(7)}$

$$
\frac{M_{t}}{M_{\infty}}=\left[1-\sum_{0}^{\infty} \frac{8}{(2 n+1)^{2} \pi^{2}} \exp \left[\frac{-D(2 n+1)^{2} \pi^{2} t}{4 l^{2}}\right]\right]
$$


where $\mathrm{M}_{\mathrm{t}}$ is the mass uptake at time $\mathrm{t}, \mathrm{M}_{\infty}$ is the maximum or ultimate mass uptake, and $l$ is the half thickness of the polymer film. Equation 3 can be rewritten as:

$$
\frac{M_{t}}{M_{\infty}}=2\left(\frac{D \cdot t}{l^{2}}\right)^{\frac{1}{2}} \cdot\left[\pi^{\frac{-1}{2}}+2 \sum_{1}^{\infty}(-1)^{n} \operatorname{ierfc} \frac{n l}{\sqrt{D t}}\right]
$$

However, when values of $t$ are small (i.e. short time periods), Equation 4 can be rewritten as: ${ }^{(8)}$

$$
\frac{M_{t}}{M_{\infty}}=\left(4 \sqrt{\frac{D}{\pi}}\right) \cdot \frac{\sqrt{t}}{2 \cdot l}
$$

Equation 5 shows that by plotting $\frac{M_{t}}{M_{\infty}}$ vs. $\frac{t^{\frac{1}{2}}}{2 l}$, the diffusion coefficient of alkaline solution through GFRP can be calculated from the slope of the linear portion of the plot. 


\section{CHAPTER 3}

\section{EXPERIMENTAL}

\subsection{Materials}

DION ${ }^{\circledR} 31040-00$ urethane hybrid pultrusion resin obtained from Reichhold Inc. was used as the polymer to prepare urethane GFRP samples. The urethane resin contained $34.50 \mathrm{wt} \%$ styrene monomer and $61.50 \mathrm{wt} \%$ polymer solids ( $4 \mathrm{wt} \%$ hydroxypropyl methacrylate). DION® 9800-05A urethane-modified vinyl ester resin was also obtained from Reichold Inc. and was used to prepare UMVE (urethane modified vinyl ester) GFRP samples. The resin was composed of $46 \mathrm{wt} \%$ styrene monomer and $54 \mathrm{wt} \%$ vinyl ester resin.

Bi-directional $\left(0^{\circ} / 90^{\circ}\right)$ E-glass fiber matting was used as the composite fiber source. The Eglass matting was obtained from Vectorply Corporation with an area density of $543 \mathrm{~g} / \mathrm{m}^{2}$. The thickness of the fiber mat was measured to be $0.12 \mathrm{~cm}$.

\subsection{Sample Preparation}

GFRP samples were prepared by placing two identical E-glass fiber sheets, each $33.02 \mathrm{~cm} \mathrm{x}$ $16.51 \mathrm{~cm}$, one on top of the other on an aluminum plate and pouring $110-130 \mathrm{~g}$ of either urethane or UMVE (urethane modified vinyl ester) resin which had been mixed with $1 \mathrm{wt}$. \% of initiator (2-Butanone peroxide) and $0.03 \mathrm{wt} . \%$ promoter (cobalt naphthenate). The mixture had been mechanically mixed with a stirrer and then placed in a vacuum chamber for 5 minutes to remove any entrapped air. After evenly distributing the resin over the two sheets, another aluminum plate was placed on top of the resin / E-glass mixture. Small weights were then placed on top of the aluminum sheet to force any trapped gasses out of the curing resin to reduce voidage in the finished samples. The sample sheet was allowed to cure at ambient temperature for at least 24 hours, and then removed from the aluminum plates. The sample sheet was then 
post-cured at $100^{\circ} \mathrm{C}$ for 3 hours in a furnace to produce a GFRP sheet with an approximate fiber volume fraction of $32 \%$.

The urethane and UMVE sample sheets were cut into strips of $29.21 \mathrm{~cm}$ x $2.54 \mathrm{~cm}$ using a wet saw to ensure no damage to the composite fiber. The sample strips were cut such that the primary load bearing fibers were in the direction measuring $20.21 \mathrm{~cm}$, and transverse fibers in the short direction, $2.54 \mathrm{~cm}$. GFRP samples prepared had an average thickness of $0.135 \mathrm{~cm}$ with very little deviation.

\subsection{Void Fraction Measurement}

Void fractions of the cured samples were measured to ensure that voidage from trapped air had no measurable effect on mechanical properties of the GFRP samples. For non-aged urethane GFRP, the average void fraction was determined to be $0.95 \%$. The voidage for non-aged UMVE GFRP was found to be $1.04 \%$. A void fraction below $1.10 \%$ is said to have no significant effect on the tensile strength of the composite. ${ }^{(9)}$ The fiber volume percentage of UMVE and urethane GFRPs was found to be 32.1 vol. \% and 31.4 vol. \%, respectively. The void fractions and fiber volume percentages of the prepared composites were determined using ASTM D 2584 ${ }^{(10)}$ and ASTM D 2734. ${ }^{(11)}$ Samples measuring $2.54 \mathrm{~cm}$ x $2.54 \mathrm{~cm}$ were cut from each GFRP sheet. The edges of the samples were gently sanded to remove any excess fibers protruding from the sample. The samples were then cleaned and dried. Using a caliper $(0.02$ $\mathrm{mm}$ accuracy), the samples were measured 3 times in each dimension ( 9 measurements in total per sample). The measurements were averaged for each dimension and then used to calculate a precise volume of each sample. Using the ignition loss method, the samples were then placed in a furnace at $575^{\circ} \mathrm{C}$ to burn away the polymer. The remaining fibers were then weighed and the change in mass was used to calculate the fiber weight percentage with the following equation: 


$$
\text { Fiber weight } \%=\left(\frac{W_{2}}{W_{1}}\right) * 100
$$

where $\mathrm{W}_{\mathrm{c}}$ is the original mass of the $2.54 \mathrm{~cm}$ square composite sample and $\mathrm{W}_{\mathrm{g}}$ is the mass of glass fibers remaining after burning off the polymer. The fiber volume percentage can also be calculated from the acquired data using the following equation.

$$
\text { Fiber volume } \%=\left(\frac{W_{2}}{d_{g} \cdot v_{s}}\right) * 100
$$

where $d_{g}$ is the density of the E-glass fiber and $v_{s}$ is the volume of the sample calculated from the measured dimensions. The density of the glass fiber was determined to be $2.565 \mathrm{~g} / \mathrm{cm}^{3}$.

From ASTM D 2734, the void fraction of the samples was calculated using Equation 8.

$$
V=100-M_{d}\left(\frac{r}{d_{r}}+\frac{g}{d_{g}}\right)
$$

where $\mathrm{V}$ is the void fraction of the $2.54 \mathrm{~cm}$ square sample, $\mathrm{M}_{\mathrm{d}}$ is its measured density, $\mathrm{r}$ is the weight $\%$ of resin, $\mathrm{d}_{\mathrm{r}}$ is the polymer density, and $\mathrm{g}$ is the weight $\%$ of glass in the GFRP sample.

\subsection{Tensile Strength Measurement}

The tensile strength was determined by ASTM D 3039. ${ }^{(12)}$ The ASTM method required the attachment of tapered reinforcing tabs on both ends of the samples for measurement of the tensile strength. The tapered tabs were prepared by cutting $2.54 \mathrm{~cm} \times 5.08 \mathrm{~cm}$ tabs from a fiberglass tile (approximately $3.24 \mathrm{~mm}$ thick). Each tab was then tapered by sanding and glued to the GFRP sample using Plio Grip 7770/660 purchased from Ashland Chemical Company.

The UMVE and urethane GFRP samples were then tested for tensile strength using an Instron 5567 machine. Tensile strength was calculated by using the maximum applied force and then dividing the max force by the cross-sectional area of the respective GFRP sample. 


\subsection{Aging Test with Load}

The experimental apparatus as shown in Figure 2 was used for sustained load aging tests.

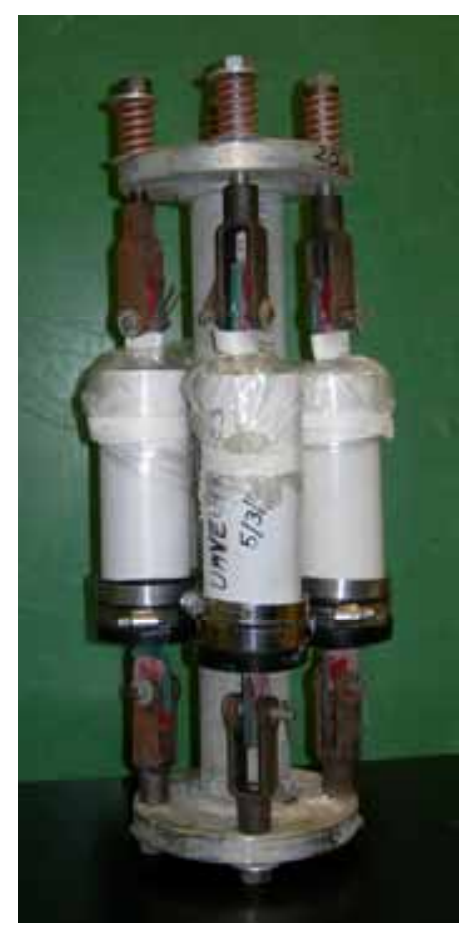

Figure 2. Sustained load test assembly

It consisted of a steel frame, an alkaline solution reservoir, and spring set. Each experiment lasted for 6 months. The cylindrical reservoir was made of a $16.5 \mathrm{~cm}$ x $5.08 \mathrm{~cm}$ PVC pip to hold the alkaline solution together with a GFRP composite sample. A $2.54 \mathrm{~cm}$ long cut was made at the center of a $5.08 \mathrm{~cm}$ diameter rubber cap. The cut was used as an entrance for the GFRP sample to slide through the rubber cap. After the GFRP sample was placed through the cut of the rubber end cap, Product \#711 epoxy obtained from Epoxy Systems Incorporated was mixed and then used to seal the GFRP samples to the rubber end caps. The epoxy mixture not only served to attach the end cap to the GFRP sample but also created a water tight and corrosion resistant seal.

When the epoxy mixture finished curing, reinforcing tabs cut from fiberglass tiles were attached to both ends of the GFRP samples using the Plio Grip. The reinforcing tabs were 
sanded into a wedge shape and attached to both ends of the GFRP samples. Figure 3 shows the side view of a GFRP sample with reinforcing tabs attached to one end.

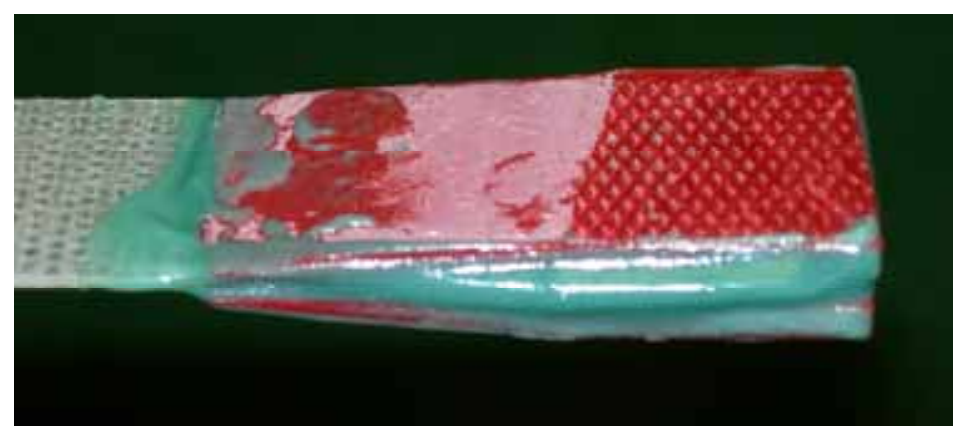

Figure 3. Reinforcement tabs after application to sample - side view

After the reinforcing tabs were secured to the GFRP sample, the PVC pipe was fit around the GFRP sample and into the rubber cap. Epoxy System's Product \#711 was used again to seal the PVC pipe to the inside of the rubber end cap.

The ends of each GFRP sample had $0.635 \mathrm{~cm}$ diameter holes drilled through the center of the reinforcing tabs. The holes allowed for metal pins to be placed through the reinforcing tabs in order to securely place the sample in the test frame under sustained load.

To apply the required load to the samples, springs were used in the testing frame. Each spring was tested using the Instron machine to find its spring constant. The required 34.5 MPa stress (16- $20 \%$ of the tensile strength) was used to find the necessary spring displacement distance by multiplying the stress by the cross-sectional area of the sample, and then dividing by the spring constant. This value (approximately $7.6 \mathrm{~mm}$ ) was used to create the necessary stress in the sustained load testing frame.

Approximately $300 \mathrm{ml}$ of an alkaline solution was then poured into the PVC pipe. The alkaline solution was composed of $0.32 \mathrm{M} \mathrm{NaOH}, 0.17 \mathrm{M} \mathrm{KOH}$, and $0.07 \mathrm{M} \mathrm{Ca}(\mathrm{OH})_{2}$. The solution concentration is approximately that of Portland cement concrete pore solution, with a 
measured $\mathrm{pH}$ of 13.4. ${ }^{(13)}$ Plastic bags were then placed over the tops of the PVC pipes and secured with tape to reduce the loss of the solution by evaporation.

The samples were removed from the frame after 6 months. The PVC pipe was cut away from the sample using a wet saw. The sample was then tested for tensile strength using an Instron Model 5567 machine. Results of the test were then compared to the tensile strength of non-aged GFRPs to determine the effect of aging with stress.

\subsection{Aging Test without Load}

Aging tests without load were conducted with 12 samples of both UMVE and urethane GFRPs. The samples were submerged in 4 liters of alkaline solution ( $\mathrm{pH} \sim 13.4)$ for 6 months. After the 6 month period, the samples were removed from the solution. Reinforcement tabs were applied to the ends of the samples and then measured for tensile strength using the Instron machine. The tensile strength was then compared with the tensile strength of non-aged samples as well as strength results from the aging with load study.

\subsection{Absorption Test for UMVE and urethane GFRP}

Twelve samples of each UMVE and urethane GFRPs were submerged in 4 liters of alkaline solution. The samples were taken out daily, dried, and then weighed. The change in mass was used to plot $M_{t} / M_{\infty}$ vs. $t^{1 / 2} / 2 \iota$ for all samples, where $M_{t}$ is the mass uptake at time $t, M_{\infty}$ is the maximum / ultimate mass uptake, $t$ is time in hours, and $\iota$ is the half thickness of the GFRP sample. According to Equation 5, the plot should yield a straight line in the early stage, and the diffusion coefficient should be determined from the slope of the linearity. 


\subsection{Absorption Test for Neat Resin UMVE and Urethane}

Absorption experiments with $2.54 \mathrm{~cm} \times 29.21 \mathrm{~cm}$ neat resin samples of both polymers were conducted. Twelve neat resin UMVE and twelve neat resin urethane samples were placed in 4 liters of alkaline solution and weighed daily. When each polymer sample reached a constant maximum value, the experiment was stopped, and the diffusion coefficient for each sample was calculated using the Fickian diffusion plot. 


\section{CHAPTER 4}

\section{RESULTS}

\subsection{Tensile Strength Measurement}

Non-aged samples of urethane and UMVE (urethane modified vinyl ester) GFRP were tested to determine their tensile strength in order to establish a baseline of comparison for the remaining experiments. The stress - strain relationship of the two sample types generally demonstrated consistent values of Young's modulus and tensile strength among the samples tested. A tabular comparison of UMVE and urethane GFRP is seen in Table 1.

Table 1. Comparison of Non-aged Mechanical Properties between UMVE and Urethane GFRP Samples

\begin{tabular}{|c|c|c|}
\hline & $\begin{array}{c}\text { Avg. Young's } \\
\text { Modulus (GPa) } \\
\text { (Std. Deviation) }\end{array}$ & $\begin{array}{c}\text { Avg. Ultimate Tensile } \\
\text { Strength (MPa) } \\
\text { (Std. Deviation) }\end{array}$ \\
\hline UMVE GFRP & $12.5(1.4)$ & $219.5(18.7)$ \\
\hline Urethane GFRP & $12.6(1.5)$ & $204.7(34.2)$ \\
\hline
\end{tabular}

Statistically, the Young's modulus for the two different samples appears to be the same. Although not statistically significant, the average tensile strength of the UMVE GFRPs appears to be slightly higher. The tensile strength values obtained from the non-aged GFRP samples can now be used as a control for comparison to tensile strength values from aged samples.

\subsection{Aging Test with Load}

Twelve urethane GFRP samples were exposed to alkaline solution under sustained stress for 6 months. Three urethane GFRP samples did not complete the 6 month testing period due to early failure. The remaining 9 samples were subjected to mechanical property testing. Two of the 
nine samples tested produced extremely inconsistent and erratic data. As a result, only 7 of the initial 12 urethane GFRP samples produced reliable tensile strength data.

The three failed samples either experienced tab failures, epoxy failures, or sample solution breaks. Tab failures indicate a separation of the reinforcement tabs from the sample. When the reinforcement tabs fail, the stress from the testing frame resulted in the GFRP sample ripping away from the frame brackets. An epoxy failure implies that a sample broke inside the epoxy at the bottom of the PVC pipe. It is believed that the rigid epoxy may serve as a severe stress concentration point for any unintended movement of the GFRP sample during the test. Sample solution breaks result when the sample breaks somewhere along the submerged portion of the sample.

Results for the aging with load study for both types of GFRP samples can be seen in Table 2 . Table 2. Tensile Strength Results for Aging with Load

\begin{tabular}{|c|c|c|}
\hline Sample & $\begin{array}{c}\text { Urethane GFRP } \\
(\mathrm{MPa})\end{array}$ & $\begin{array}{c}\text { UMVE GFRP } \\
(\mathrm{MPa})\end{array}$ \\
\hline 1 & 65.4 & 149.5 \\
\hline 2 & 109.2 & 160.9 \\
\hline 3 & 52.7 & 137.4 \\
\hline 4 & 105.4 & 166.3 \\
\hline 5 & 87.3 & 178.7 \\
\hline 6 & 95.6 & 143.0 \\
\hline 7 & 92.4 & 170.8 \\
\hline 8 & ------- & 170.9 \\
\hline Average (Std. Deviation) & $86.9(20.7)$ & $159.7(14.8)$ \\
\hline
\end{tabular}

The aging with load data for the urethane GFRPs appears somewhat erratic. A slightly increased deviation for the urethane GFRP samples in Table 2 should also be noted. One can see from Table 2 that the tensile strength of urethane GFRP samples drastically decreases due to aging, from 204.7 to $86.9 \mathrm{MPa}$, a $57.5 \%$ reduction. The least aged urethane GFRP sample was found to have a tensile strength of 109.2 MPa as shown in Table 2. This corresponds to a $46.7 \%$ 
reduction in tensile strength. These reduction values present a striking contrast to the reduction in tensile strength of vinyl ester GFRP subjected to aging under the same conditions, which was only $7.7 \%$ in a previous study. ${ }^{(14)}$

Table 2 also shows the results of aging with load for UMVE GFRP samples. Twelve UMVE GFRP samples in total were tested. Four samples were eliminated due to relatively large deviations in tensile strength results. The UMVE GFRP tensile strength was reduced by $27.3 \%$ over the 6 month testing period, which is a significant improvement when compared with the $57.5 \%$ tensile strength reduction shown by the urethane GFRP samples.

\subsection{Aging Test without Load}

Unlike the aging test with load, the 6 month aging test without load resulted in negligible effects on the tensile strength of the urethane and UMVE GFRP samples when compared with their non-aged counterparts. Table 3 shows the results from the test for both types of GFRP samples.

Table 3. Tensile Strength Results for Aging without Load

\begin{tabular}{|c|c|c|}
\hline Sample & $\begin{array}{c}\text { Urethane GFRP } \\
(\mathrm{MPa})\end{array}$ & $\begin{array}{c}\text { UMVE GFRP } \\
(\mathrm{MPa})\end{array}$ \\
\hline 1 & 214.4 & 218.9 \\
\hline 2 & 199.9 & 209.8 \\
\hline 3 & 195.4 & 209.6 \\
\hline 4 & 190.3 & 213.0 \\
\hline 5 & 200.2 & 179.3 \\
\hline 6 & 183.8 & 200.7 \\
\hline 7 & 181.8 & 224.2 \\
\hline 8 & 175.5 & 162.4 \\
\hline Average (Std. Deviation) & $192.6(12.5)$ & $202.3(21.1)$ \\
\hline
\end{tabular}

The tensile strength of the urethane GFRP decreased by only 5.9\%, which is much lower than the $57.5 \%$ reduction with load. The large aging effect due to sustained stress is very clear when comparing with the results of aging test without load. The standard deviation of the urethane 
GFRP samples was $12.5 \mathrm{MPa}$ or $6.5 \%$ of the measured value. When taking the standard deviation into consideration, the slight reduction in tensile strength for the urethane GFRP samples appears to be statistically insignificant.

The aging test without load for UMVE GFRP also resulted in negligible changes in the tensile strength of the aged samples. Table 3 shows that the average tensile strength of the aged UMVE GFRP samples is 202.3 MPa which is within the margin of error of the original non-aged UMVE GFRP samples (as shown in Table 1). Because the measured value lies within the margin of error for the original non-aged samples, it is difficult to say whether the reduction in the tensile strength for the UMVE GFRP samples is real.

\subsection{GFRP Absorption Test}

The results of the absorption study for urethane GFRPs are plotted according to Equation 5 and shown in Figure 4. The plot is based on the Fickian model and is in a convenient form to determine the diffusion coefficients. As seen from Figure 4, there are three diffusion zones: the first where the mass increases until it peaks around 10 days; in the second zone the mass decreases until around 30 days; and in the third zone the steady state mass is maintained. The first zone is believed to be predominantly absorption phase of the alkaline solution; the second zone is for also predominantly dissolution of the fiber by alkaline solution and then desorption of dissolution products; and the third zone is a steady state phase that shows a balance of the two previous zones.

The first zone (absorption zone) from Figure 4 is expanded in Figure 5. From the best-fit slope $\left(0.0125 \mathrm{~cm} / \mathrm{hr}^{1 / 2}\right)$ the diffusion coefficient for urethane GFRPs in alkaline solution was calculated to be $8.52 \times 10^{-9} \mathrm{~cm}^{2} / \mathrm{s}$. This value can be compared with the diffusion coefficient of vinyl ester GFRP which is recorded as $5.36 \times 10^{-9} \mathrm{~cm}^{2} / \mathrm{s}$ in a previous study. ${ }^{(14)}$ 


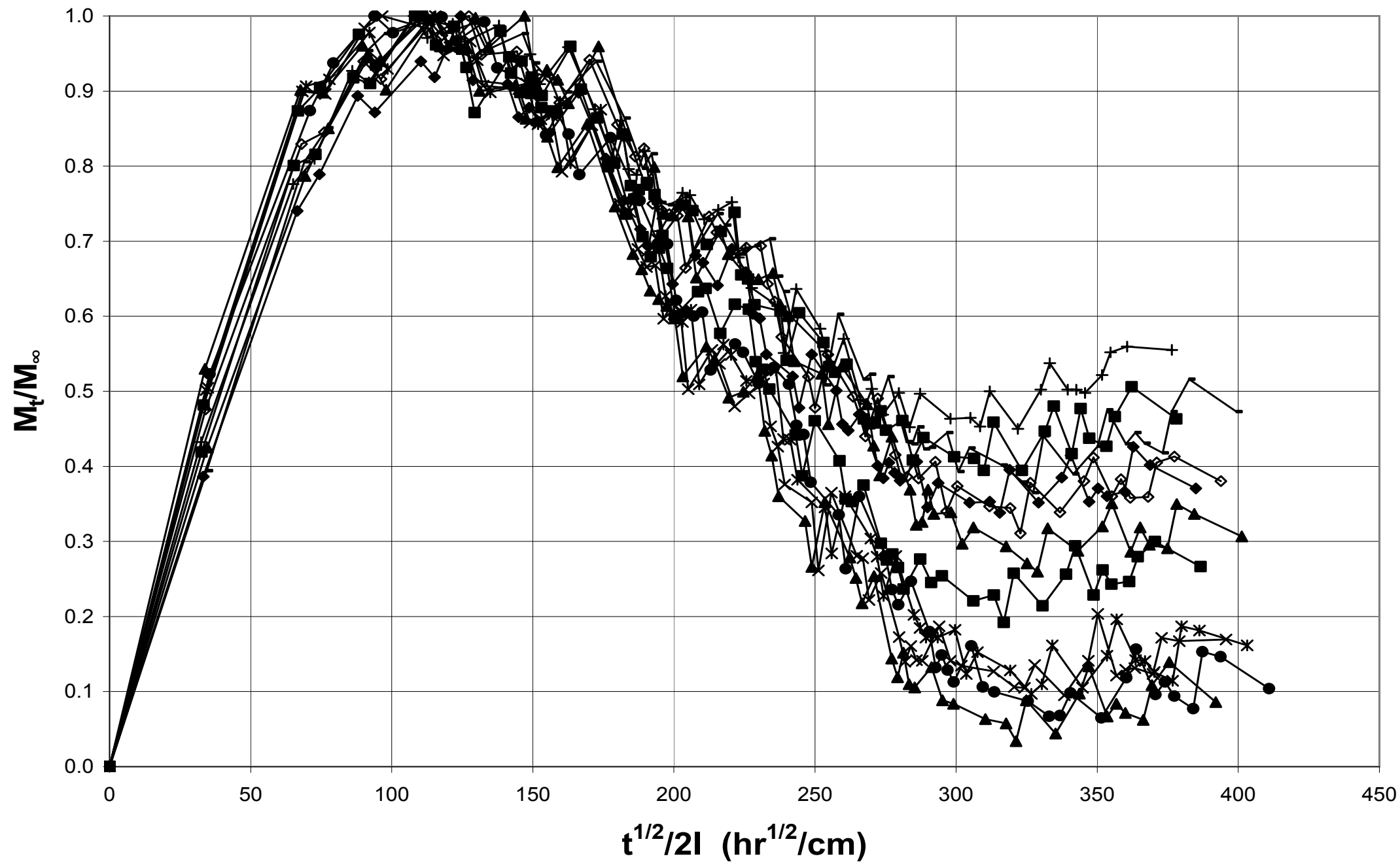

Figure 4. Plot according to Fickian model for absorption of alkali into urethane GFRP 


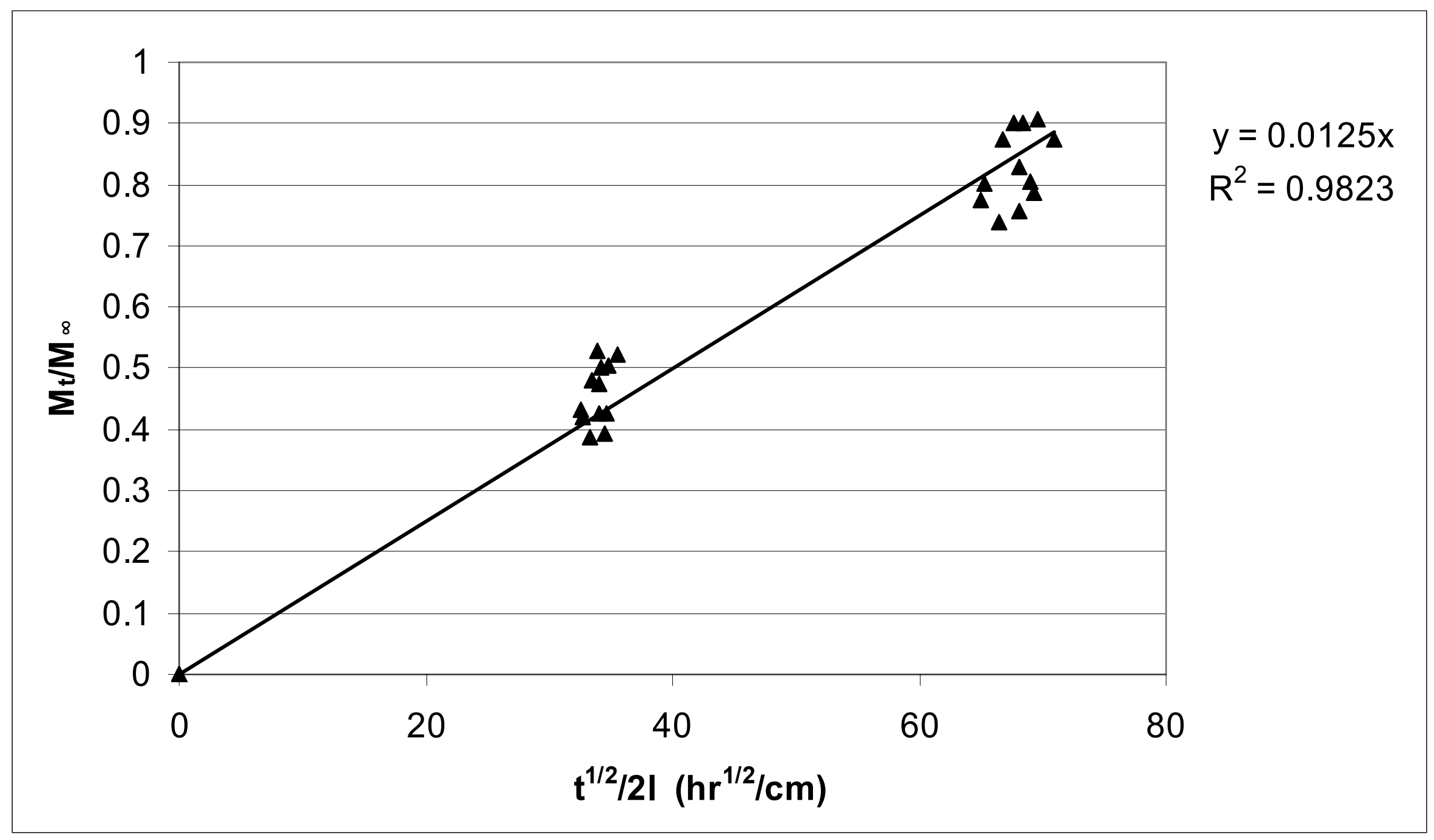

Figure 5. Linear plot for the early stage absorption into urethane GFRP 
The former value is $59 \%$ higher than the latter value. This differential in diffusivity may be the reason, at least partially responsible, for the huge change in tensile strength observed for urethane GFRP vs. vinyl ester GFRP, $57.5 \%$ vs. 7.7\%, respectively.

The same type of absorption study with UMVE GFRP was conducted and the results are plotted according to the Fickian model, shown in Figure 6. The absorption curves follow the same trend as for urethane GFRP (see Figure 4). The samples reached a maximum mass after approximately 5 days of alkaline solution exposure, and then proceeded to follow the same loss of mass as seen with the urethane GFRP samples. However, the UMVE GFRP samples continued to lose mass beyond their original masses which resulted in negative values, as shown in Figure 6. The mass of the samples stabilized after approximately 130 day exposure in alkaline solution.

The samples' loss of mass below their original starting values would suggest that an attack on the fiber phase by the alkaline solution is more severe in UMVE GFRP than in urethane GFRP. However, this could not be the case because the tensile strength reduction due to aging is greater with urethane GFRP than with UMVE GFRP. Thus, the mechanism responsible for the reduction in the tensile strength and the loss of mass below the starting value cannot be related at this time.

Figure 7 expands the first stage of Figure 6 and shows the initial linear data for the UMVE GFRP samples. The diffusion coefficient for UMVE GFRP was determined from the initial slope and found to be $11.0 \times 10^{-9} \mathrm{~cm}^{2} / \mathrm{s}$, with a standard deviation of $1.71 \times 10^{-9} \mathrm{~cm}^{2} / \mathrm{s}$. This diffusion coefficient is larger than the coefficient obtained for urethane GFRP. The larger diffusion coefficient of UMVE GFRP implies a faster absorption of alkaline solution during aging. 


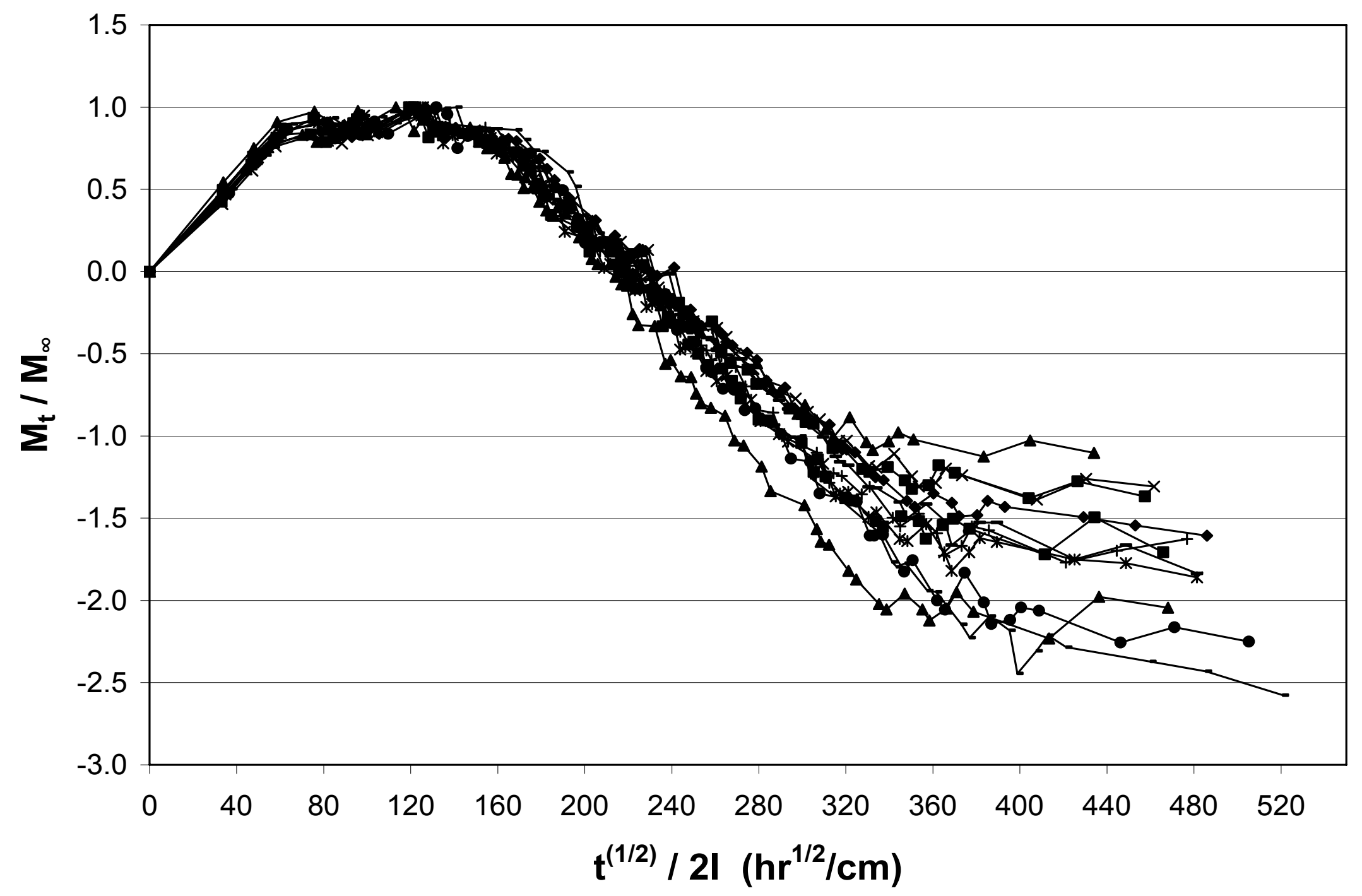

Figure 6. Plot according to Fickian model for absorption of alkali into UMVE GFRP 


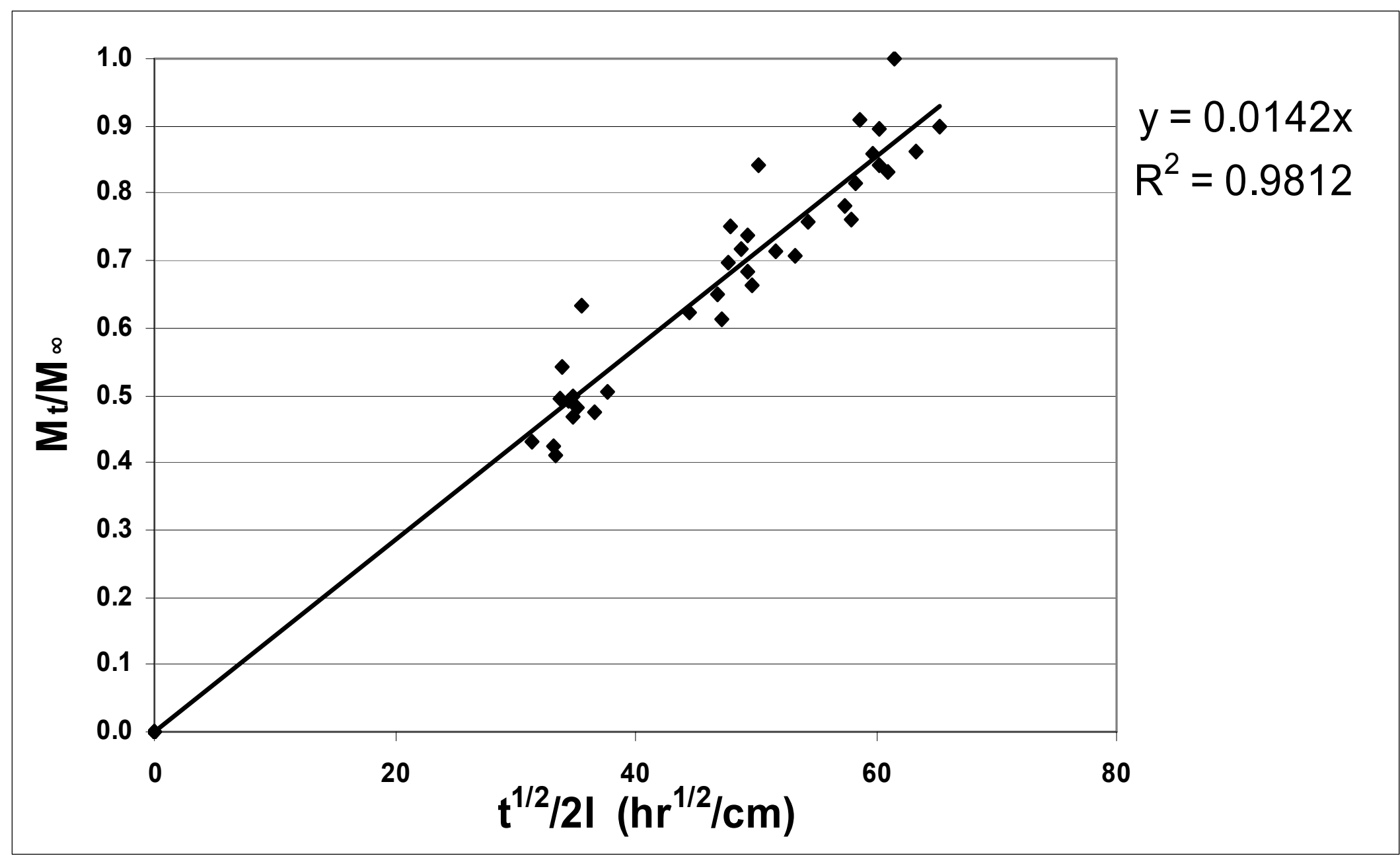

Figure 7. Linear plot for the early stage absorption into UMVE GFRP 
It appears then that the faster absorption of the alkaline solution is responsible for the loss of mass below the original mass of the UMVE GFRP samples through dissolution of the fiber.

\subsection{Absorption Test with Neat Urethane and UMVE}

Twelve urethane neat resin samples were used for absorption experiments. The results are also plotted according to the Fickian model, and shown in Figure 8. From the data in the early stage, the diffusivity of alkali through the urethane neat resin was found to be $7.8 \times 10^{-9} \mathrm{~cm}^{2} / \mathrm{s}$. Figure 8 also confirms the absorption characteristics of neat polymer samples versus composite samples prepared with the same polymer resin. Unlike the Fickian model plot for urethane GFRP (Figure 6), the neat resin Fickian model reaches its maximum moisture content and maintains it, which suggests that the resin matrix of urethane is not dissolved by the alkaline solution.

The same type of plot is made for the absorption of alkali on the neat UMVE resin samples, and is shown in Figure 9. From the data in the early stage of the alkali adsorption, the diffusivity was determined to be $7.6 \times 10^{-9} \mathrm{~cm}^{2} / \mathrm{s}$, which falls well within the margin of error calculated for the urethane neat resin data $\left(7.8 \times 10^{-9} \mathrm{~cm}^{2} / \mathrm{s}\right)$. The alkaline solution diffusion coefficients of the two neat resin samples (urethane and UMVE) confirm that when no glass fiber is present, the diffusion characteristics are very similar. However, when glass fibers are present, the diffusion rate of the alkaline solution through the UMVE GFRP seems to be slightly faster than the urethane. Table 4 summarizes and compares the diffusion coefficients from the 4 absorption experiments. 


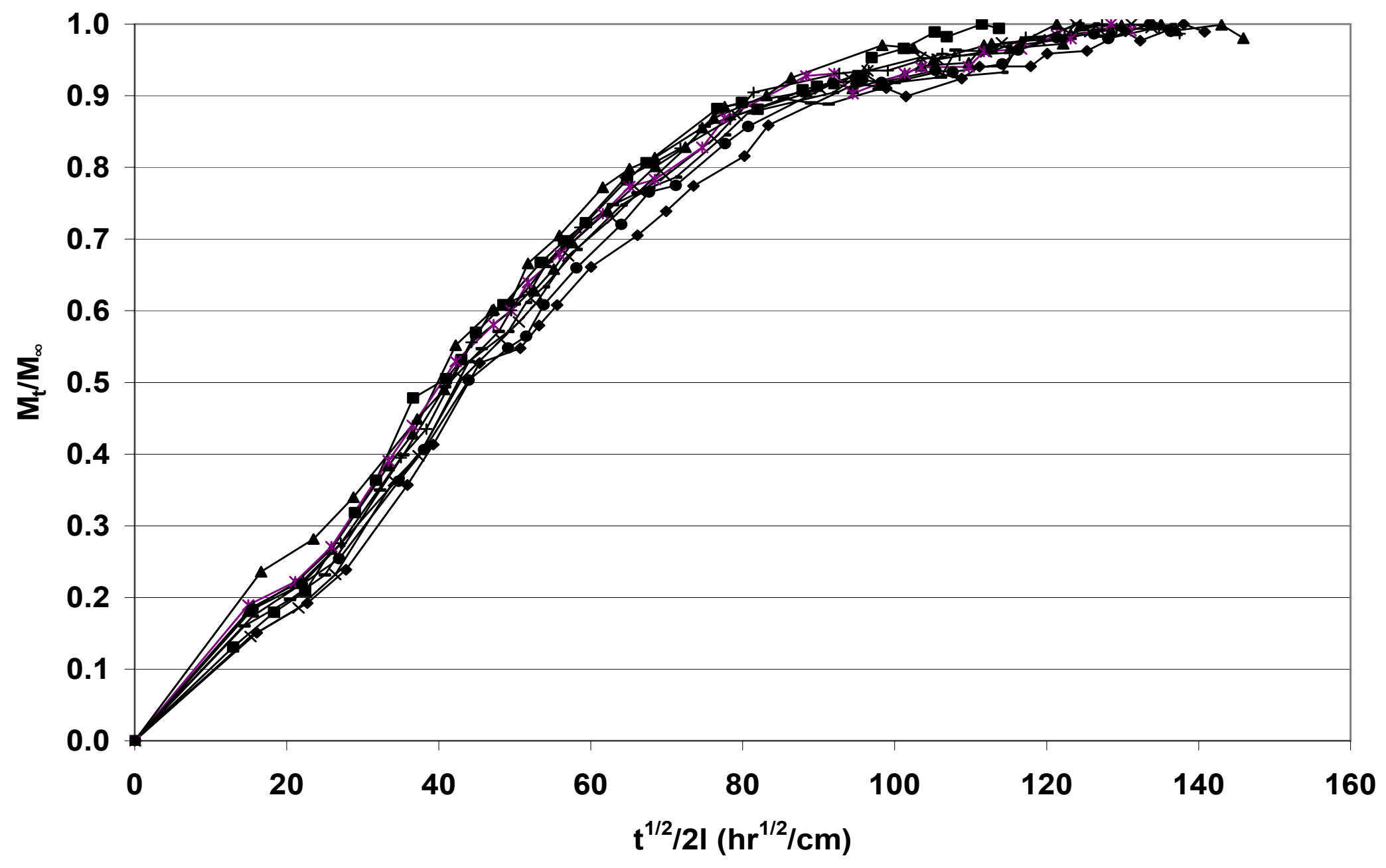

Figure 8. Plot according to Fickian model for absorption of alkali into urethane neat resin 


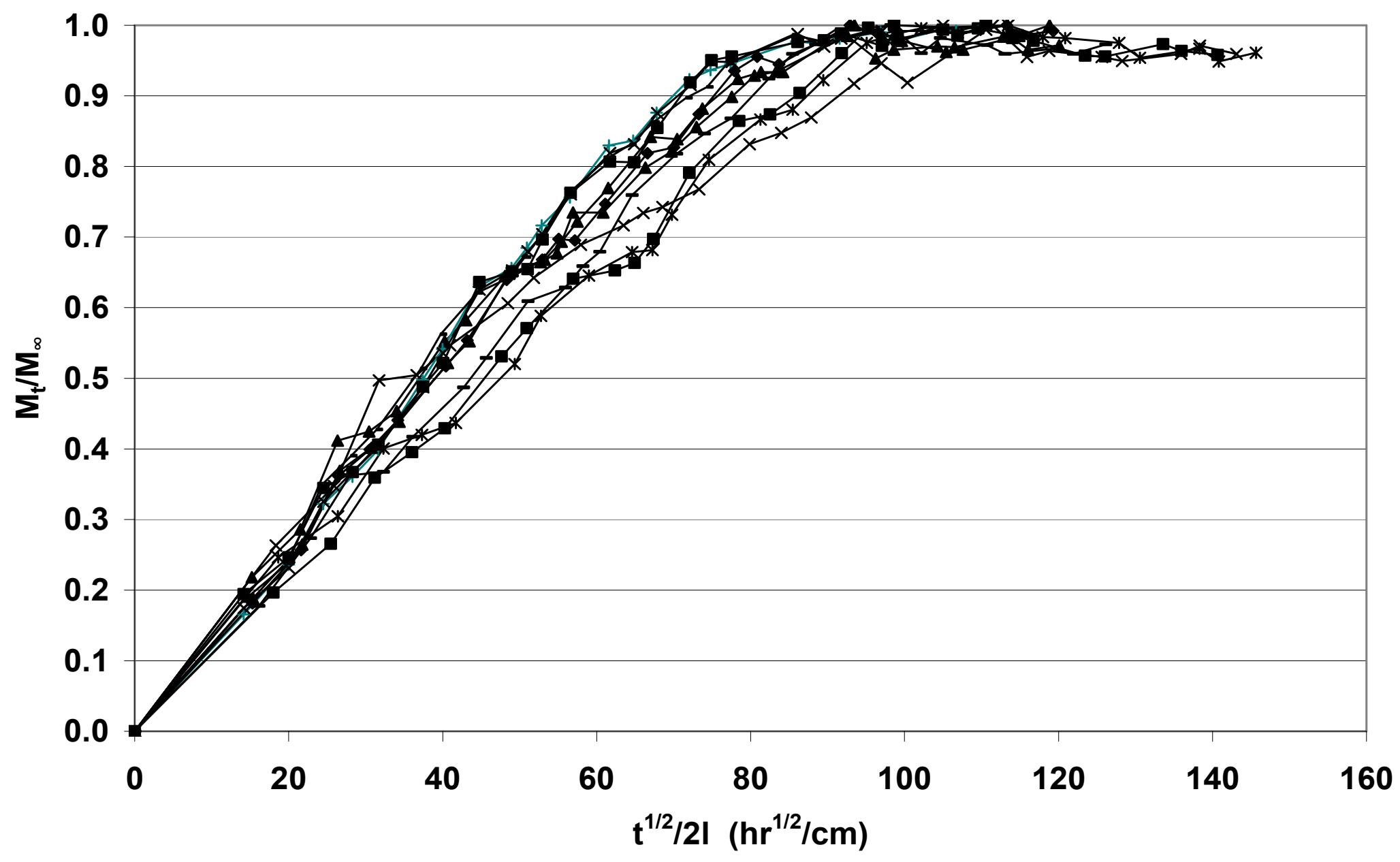

Figure 9. Plot according to Fickian model for absorption of alkali into UMVE neat resin 
Table 4. Diffusion Coefficients for GFRPs and Neat Resins

\begin{tabular}{|c|c|c|}
\hline & $\begin{array}{c}\text { Peak / Ultimate } \\
\text { Moisture Content }(\%)\end{array}$ & $\begin{array}{c}\text { Diffusion Coefficient } \\
\left(\mathrm{x} 10^{-9} \mathrm{~cm}^{2} / \mathrm{s}\right)\end{array}$ \\
\hline Urethane GFRP & 0.52 & 8.5 \\
\hline UMVE GFRP & 0.11 & 11.0 \\
\hline Urethane Resin & 0.92 & 7.8 \\
\hline UMVE Resin & 0.40 & 7.6 \\
\hline
\end{tabular}

The peak / ultimate moisture contents given in Table 4 may present a clue as to the distinct aging behavior between urethane and UMVE GFRPs. It is apparent that the moisture sorption capacity of the neat urethane resin is much greater than that of UMVE neat resin. This can be judged from the two values of the ultimate moisture content, $0.92 \%$ vs. $0.4 \%$, respectively. This trend is also revealed in the peak moisture content of the two GFRPs. The peak moisture content of urethane GFRP is almost five times as much when compared to the UMVE GFRP. This large differential may be responsible for the mechanism with which urethane GFRP is more severely aged than UMVE GFRP in spite of the fact the absorption characteristics of UMVE GFRP, such as the loss of mass below its original value, go against this premise. This distinct difference on the peak / ultimate absorption content between urethane resin and urethane modified vinyl ester may be explained in terms of structural characteristics of the two resins in that urethane is more hydrophilic than vinyl ester. ${ }^{(15)}$ 


\section{CHAPTER 5}

\section{CONCLUSIONS}

- Urethane GFRP samples aged more severely in alkaline solution under a sustained stress of $34.5 \mathrm{MPa}$ than UMVE GFRP samples. The reduction in tensile strength values for the urethane and UMVE GFRPs were $57.5 \%$ and $27.3 \%$, respectively.

- The 6-month aging without load test for urethane and UMVE GFRP samples resulted in no significant change in tensile strength. The urethane GFRP tensile strength decreased by only $5.9 \%$ to $192.6 \mathrm{MPa}$, which was within the margin of error for the measured non-aged urethane GFRP samples. The UMVE GFRP aging without load samples averaged a tensile strength of $202.3 \mathrm{MPa}$ which was also well within the margin of error set by the measurement of non-aged samples.

- The diffusion coefficients of alkaline solution through urethane and UMVE GFRP samples were $8.52 \times 10^{-9}$ and $11 \times 10^{-9} \mathrm{~cm}^{2} / \mathrm{s}$, respectively, both of which are higher than that of vinyl ester GFRP $\left(5.36 \times 10^{-9} \mathrm{~cm}^{2} / \mathrm{s}\right)$ recorded in a previous study.

- Diffusion coefficients for the neat resin samples were determined to be nearly the same. The diffusion coefficients for urethane and UMVE neat resin samples were $7.8 \times 10^{-9}$ $\mathrm{cm}^{2} / \mathrm{s}$ and $7.6 \times 10^{-9} \mathrm{~cm}^{2} / \mathrm{s}$, respectively.

- The peak moisture uptakes of the alkaline solution for urethane and UMVE GFRP samples were significantly different from one another, $0.52 \%$ vs. $0.11 \%$, respectively. This differential may be the primary reason for the distinct aging effects of the two GFRP samples, in terms of tensile strength reduction. 


\section{REFERNCES}

1. Liao, K., "Long-term Durability of Fiber-Reinforced Polymer-Matrix Composite Materials for Infrastructure Applications: A Review," Journal of Advanced Materials, 1998, Vol. 30, n 4, pp. 3-40.

2. Rostasy, F.S., "FRP: The European Perspective," ICCI'96, Fiber Composites in Infrastructure, Edited by Saadatmanesh H. and Ehsani M.R., 1996, pp. 12-20.

3. Vijay, P.V., GangaRao, Hota, "Final Report: Development of Fiber Reinforced Plastics for Highway Applications (Task A2),” 2005.

4. Karbhari, V.M., Murphy, K., Zhang, S., "Effect of Concrete Basked Alkali Solutions on Short-Term Durability of E-Glass/Vinylester Composites.” Journal of Composite Materials, 2002, Vol. 36 Issue 17, p 2101.

5. Holmes, T.M., Leatherman, G.L. and El-Korchi, T., "Alkali-Resistant Oxynitride Glasses," Journal of Materials Research, 1991, 6(1), pp. 152-158.

6. Aniskevich, K., Hristova, J., Jansons, J. "Sorption Characteristics of Polymer Concrete During Long-term Exposure to Water," Mechanics of Composite Materials, 2003, Vol. 39, No. 4, pp. 1-2.

7. Crank, J. and Park, G.S. "Diffusion in Polymers," Academic Press, London and New York, 1968.

8. Singh, K.S., Singh, P.N. and Rao, R.M.V.G.K. "Hygrothermal Effects on Chopped Fiber/Woven Fabric Reinforced Epoxy Composites. Part A. Moisture Absorption Characteristics,” J. Reinforced Plastic Composites, 1991, vol. 10, pp. 446-456.

9. Guo, Z., Liu, L., Zhang, B., and Du, S. "Critical Void Content for Thermoset Composite Laminates," J. of Composite Materials, 2006, pp 10-15.

10. ASTM D 2584, "Standard Test Method for Ignition Loss of Cured Reinforced Resins," Annual Book of ASTM Standards. American Society of Testing Materials, West Conshohocken, 2000.

11. ASTM D 2734, "Standard Test Methods for Void Content of Reinforced Plastics," Annual Book of ASTM Standards. American Society of Testing Materials, West Conshohocken, 2000.

12. ASTM D 3039, "Standard Test Method for Tensile Properties of Polymer Matrix Composite Materials," Annual Book of ASTM Standards, American Society of Testing Materials, West Conshohocken, 2000. 
13. Christensen, B.J., Mason, T.O. and Jennings, H.M. "Influence of Silica Fume on the Early Hydration of Portland Cements using Impedance Spectroscopy,” J. of Amer. Ceramics Soc., 1992, Vol. 75, pp. 939.

14. Ravindran, Naveenkamal and Cho, E. H., "Durability of Glass-Fiber-Reinforced Polymer Nanocomposites in an Alkaline Environment," Journal of Vinyl and Additive Technology, 2006, pp. 25-32.

15. Private conversation with GangaRao, Hota, Professor, Civil and Environmental Engineering, West Virginia University, Morgantown, WV 26506, (304)293-7608 x 2634. 